\title{
Chapter 13 \\ Interface Between Antitrust Law and Intellectual Property in the Payment Systems Market in India
}

\author{
Yogesh Dubey and Konark Bhandari
}

\section{Introduction}

In one fell swoop, on 8 November 2016, the Indian government outlawed certain notes of high denomination with the result being that approximately $86 \%$ of the currency that was in circulation, lost its status as legal tender. ${ }^{1}$ The vernacular press referred to it as 'notebandi', meaning 'banning of notes'. However, irrespective of the semantics, one thing was for sure that this was a far reaching event that had irreversibly changed the course of the Indian payments industry. For instance, prior to demonetization, the usage of cashless payment as an option was popular and had increased 22\% from October 2015 to October 2016. But post-demonetization, the usage of cashless payment instruments had returned to levels that existed prior to demonetization. Except for one cashless payment instrument-Unified Payment Interface (UPI). ${ }^{2}$

In April 2015, UPI, was launched by the National Payments Corporation of India (NPCI), the umbrella organization for every retail payment system in India. ${ }^{3} \mathrm{It}$

\footnotetext{
${ }^{1}$ 'Currency in Circulation at 90\% of level before note ban' (LiveMint, 20 October 2017) <http://www. livemint.com/Politics/Zp9V2MR6szRwCwEuPjJIKK/Currency-in-circulation-at-90-of-level-before-noteban.html>.

${ }^{2}$ Dinesh Unnikrishnan, 'Shift to cashless economy: demonetisation has indeed boosted digital payments but let's not over-hype it' (Firstpost, 17 July 2017) <http://www.firstpost.com/business/shift-tocashless-economy-demonetisation-has-indeed-boosted-digital-payments-lets-not-over-hype-it-3822579. html>.

${ }^{3}$ National Payments Corporation of India, 'NPCI presents Unified Payments Interface (UPI) System' (11 April 2016) <https://www.npci.org.in/sites/default/files/UPI_Launch_Press_ Release_April_11_2016.pdf>.
}

Y. Dubey $(\varangle) \cdot K$. Bhandari

Competition Commission of India (CCI), New Delhi, India

e-mail: yogeshkr.dubey@gmail.com

(C) The Author(s) 2018

A. Bharadwaj et al. (eds.), Multi-dimensional Approaches Towards New Technology,

https://doi.org/10.1007/978-981-13-1232-8_13 
was an immediate payment system using a mobile application that would allow instantaneous money transfer between various bank accounts.

As stated by NPCI, 'UPI is a unique payment solution as the recipient is now empowered to initiate the payment request from a mobile. It facilitates 'virtual address' as a payment identifier for sending and collecting money and works on single click two factor authentication. ${ }^{4}$

Although introduced earlier in April 2016, it was only in August 2016 that the mobile applications of various participating banks became operational, ${ }^{5}$ thereby officially ushering in a new era for digital payments in India. However, it was only with the advent of demonetization that the UPI started to gain traction and witnessed swift adoption by users. The data collated post demonetization validates this statement. ${ }^{6}$ While the user friendly interface definitely helped with the rapid adoption rate, the UPI was largely successful because it was a unique payment system, heralded by many as unlike any other before it, anywhere in the world. ${ }^{7}$ Demonetization only increased the awareness of such unique and alternative payment systems.

\section{Interoperability and the Functioning of UPI}

\subsection{Working of UPI}

Aside the technical verbiage employed by the NPCI when introducing UPI, one must investigate the working of UPI. While using the UPI app, a customer can initiate a transaction by sending funds to the intended beneficiary by way of linking his bank account to his mobile number and by selecting the mobile number of the beneficiary (and provided that such beneficiary has also downloaded a UPI app). As a second step, the amount to be transferred has to be entered, followed by entering a four digit Personal Identification Number (PIN) authenticating the transaction. The attractive feature of UPI was arguably that a user could avail the UPI app of any bank, even a bank where the user did not have a bank account, to credit money from his bank account (at a different bank) to an altogether different bank account. All these happened in real time. i.e. the unique selling point was that it did not matter if the bank whose app the user was using hosted his actual account.

\footnotetext{
${ }^{4}$ ibid.

${ }^{5}$ National Payments Corporation of India, 'NPCI'S Unified Payments Interface (UPI) set to go live' (25 August 2016) <https://www.npci.org.in/sites/default/files/NPCIsUnifiedPaymentsInterface\% 28UPI\%29settogoliveAugust252016.pdf>.

${ }^{6}$ Unnikrishnan (n 2).

${ }^{7}$ Arundhati Ramanathan, 'The unlikely story Of BHIM, the upsetter of plans' The Ken (25 January 2017) <https://the-ken.com/unlikely-story-of-bhim/>.
} 


\subsection{Interoperability}

The feature of interoperability has so far remained available only to banks. In other words, other payment instruments, such as mobile wallets have thus far, not been able to avail this facility. Interoperability would permit the user of a particular type of mobile wallet to transfer or receive money from the user of a different brand of mobile wallet. Recently, a Reserve Bank of India's (RBI) Master Direction has mandated that mobile wallets must be made interoperable with one another and subsequently, at a later stage, also made interoperable with banks. ${ }^{8}$ At the outset, it means that once interoperability is operational between mobile wallets inter se, mobile wallet users of one particular company would be able to transfer funds to and from the mobile wallets of other companies. Afterwards, the second stage of interoperability will entail that mobile wallet users will also be able to transfer money to and from different bank accounts.

\subsection{Difference Between Mobile Wallets and UPI Apps}

When compared to mobile wallets, UPI apps are widely seen as more convenient and easy to use. This is due to the fact that compared to mobile wallets; they have a substantially higher transaction limit of ₹ 1 lakh per day compared to the ₹ 20,000 per month that can be transacted through mobile wallets (without Know Your Customer (KYC) and ₹ one lakh per month with KYC); are interoperable with one another; do not require frequent topping up (as they are linked to a bank account); are viewed as more secure; and do not require any tie-up with any merchants unlike mobile wallets.

Despite this, mobile wallets remain popular among all strata of users (customers and merchants), even though the adoption rate of such mobile wallets appears to be tapering. ${ }^{9}$ The most popular UPI app remains PhonePe, owned by Indian e-commerce major Flipkart and partnered with Yes Bank (since it is the bank that has the right of securing a license from RBI and while software developers can

\footnotetext{
${ }^{8}$ Suneeth Katarki, Ashi Bhat and Anoop Ashok, 'Master Direction on Issuance and Operation of Prepaid Payment Instruments' (Mondaq, 20 November 2017) <http://www.mondaq.com/india/x/ 647880/Financial+Services/Master+Directions+On+The+Issuance+And+Operation+Of+Prepaid +Payment+Instruments+In+India>.

${ }^{9}$ ibid; Mobile wallets have been arguably more adept at stealing a March over UPI apps due to their simple interface, ease of use, cashbacks, and being less prone to bugs. However, data released by the RBI for digital transactions showed that for UPI, the transaction volume saw a month on month increase of approximately $85 \%$ to 30.8 million transactions in September 2017. Further, the value of transactions rose from ₹ 4,127 Crores to ₹ 5,293 Crores in September from the previous month, an increase of $28 \%$. This in contrast to PPIs such as mobile wallets which saw a high transaction volume of 87.5 million, yet a comparatively lesser value being transacted at ₹ 2,759 Crores. Komal Gupta, 'Digital Transactions Rose $13.5 \%$ to ₹ 124.69 tn in September: RBI' (LiveMint, 2017).
} 
develop the app and implement it, the infrastructure has to be provided by the bank) with 45 million users ${ }^{10}$ : They are trailed by the government promoted BHIM app, which as per the latest press release by NPCI had 16 million users. ${ }^{11}$ This is considerably lesser than the user base of 200 million enjoyed by India's largest mobile wallet company, Paytm. ${ }^{12}$

Therefore, it is apparent that after the introduction of UPI, the UPI apps of banks have stolen a March over the likes of mobile wallets (in terms of value of transactions) owing to the factors enumerated earlier. There are certain factors that explain this impressive growth. As mentioned earlier, the biggest attraction for users when downloading a UPI app was that it was platform neutral and allowed for interoperability, i.e. it did not matter whether the user had an account at the bank whose UPI app he was downloading. The same however, has remained elusive for mobile wallets, until recently, when the RBI issued a Master Direction requiring compulsory interoperability. However, as we shall see later in the course of this chapter, even the RBI mandating interoperability among mobile wallets inter se and between mobile wallets and banks is unlikely to drive further growth for mobile wallets owing to the simultaneous tweaking of certain regulatory norms for the mobile wallets regime.

In the following paragraphs, it is analyzed that why mobile wallets were 'left out' when the feature of interoperability was being extended to banks? The reasons could possibly range from any, to all the following:

(a) Fear of mobile wallets capturing a substantial part of the banks' business: Initially, when mobile wallet companies started operations, they focused only on ancillary and niche business segments such as insurance or loan products. Once mobile wallets started to make incursions into what was regarded as the domain of banks (such as the payments business), ${ }^{13}$ the banks responded with hostility. ${ }^{14}$ State Bank of India (SBI), India's largest bank, blocked its customers from being able to transfer any money to the mobile wallet run by Paytm. ${ }^{15}$ While no senior bank

\footnotetext{
${ }^{10}$ Arundati Ramanathan, 'RBI Has Kicked off a Shark Fight for Wallet Users' The Ken (16 October 2017) <https://the-ken.com/story/rbi-kicked-off-shark-fight-wallet-users/>.

${ }^{11}$ National Payments Corporation of India, 'NPCI's BHIM App crosses 16 million downloads mark' (24 July 2017) <https://www.npci.org.in/sites/default/files/NPCI-BHIM-App-crosses-16million-downloads-mark.pdf>.

${ }^{12}$ Mugdha Variyar, 'Paytm wallet reaches 200 million users' The Economic Times (28 February 2017) <https://economictimes.indiatimes.com/small-biz/startups/paytm-wallet-reaches-200million-users/articleshow/57371236.cms>.

${ }^{13}$ Arundati Ramanathan, 'Barbarians at the Gate' The Ken (1 March 2017) <https://the-ken.com/ barbarians-at-the-gate/>.

${ }^{14}$ Goutam Das 'Shrinking Wallets' Business Today (New Delhi, 4 June 2017). It is however, debatable whether the banks were all that interested in their payments business since it's a low margin business as per most industry experts and the source of revenue thus far for banks was mostly card companies that would provide the banks a pre-determined Merchant Discount Rate every time a merchant used a bank's credit or debit card for accepting payment.

${ }^{15}$ ibid.
} 
official may go on the record and admit that mobile wallets were cannibalizing their payments business, it is not wholly inconceivable that by also making mobile wallets fully interoperable, the banks might have had to face the attendant risk of such mobile wallet companies further nibbling away at their payments business-a business which received a fillip with the advent of the UPI. Indeed, ICICI Bank did block its customers from availing the PhonePe UPI app operated by Flipkart by alleging a transgression of interoperability rules. Another potential reason could be that by extending interoperability to mobile wallets, the banks may suffer on account of lesser realization of service fees that they currently charge the mobile wallet company every time a user debits money from his bank account and into his mobile wallet. With interoperability, the mobile wallet user may also top-up his mobile wallet balance by transferring the amount from another mobile wallet and forego using a bank account linked to his mobile wallet.

(b) The regulatory architecture of NPCI: The NPCI is the body that has been responsible for introduction and implementation of UPI. It is interesting to note that the role of NPCI is nebulously defined. It is currently involved with an assortment of activities ranging from: operating a payment systems such as IMPS and UPI; being a quasi-regulator; and being an app owner in the form of BHIM. With such a variety of roles, there appears to be a conflict of interest here. At its core, the NPCI is comprised of 56 member banks, most of which have come out with their own UPI app, while at the same time, it is entrusted with defining the contours of how the UPI payment system will operate for others. This, as seen above, has been to the detriment of mobile wallet companies. This has been recognized by the Ratan Watal Committee Report on Digital Payments constituted by the Ministry of Finance, Department of Economic Affairs. ${ }^{16}$ It has been suggested that 'only bank led PSPs (payment service providers) have direct access to payment systems' ${ }^{17}$

(c) RBI's reluctance to relax regulations on mobile wallets: In addition to NPCI (which implements the UPI), the RBI has regulatory oversight of how prepaid payment instruments are governed. ${ }^{18}$ So far, the RBI too, was hesitant to allow mobile wallets to be fully interoperable because only banks were allowed to accept deposits. Since deposits are public money, the banks were tightly regulated. Mobile wallets did not enjoy regulatory scrutiny to the same extent and therefore there was a risk with interoperability. It was feared that if something goes wrong, the mobile wallet companies will not be able to recoup the losses.

\footnotetext{
${ }^{16}$ Press Information Bureau, 'Committee on Digital Payments Headed by Shri. Ratan P Watal, Principal Advisor, NITI Aayog and former Finance Secretary submits its final report to the Union Finance Minister Shri Arun Jaitley today' (9 December 2016).

${ }^{17}$ Committee on Digital Payments, 'Medium term recommendations to strengthen digital payments ecosystem' (2016).

${ }^{18}$ Katarki (n 8); All entities that have been issuing PPIs have been operating within the regulatory framework of RBl's 'Policy Guidelines for Issuance and Operation of Pre-paid Payment Instruments in India', issued on 27 April 2009, and most recently amended vide a master circular dated 1 July 2016.
} 
According to industry insiders, the RBI was taking a risk at the outset by letting mobile wallet companies to take deposits. ${ }^{19}$ With the issuance of the latest Master Directions on 11 October 2017, however, the RBI has apparently overcome any doubts about the risk involved.

(d) Exploiting the data available: Cash still remains king and is the predominant payment mode for transacting business. ${ }^{20}$ Further, there remains little clarity on how and where the cash is spent. However, whenever a user avails his bank-issued credit/debit card or net-banking, such spending pattern can be configured by the bank. With the arrival of mobile wallet companies, this became a challenge for the banks since now the users began debiting money to their mobile wallets and started spending through these wallets. The banks lost track of the spending trail and the mobile wallets became the sole repositories of such data. With their constant revision of algorithms and updating of software, mobile wallet companies are also better placed to project the trajectory of how the wallet users will use their money in future. By preventing interoperability, the NPCI sought to prevent losing further data and make all UPI app developers (who must partner with a bank as per RBI instructions) share data which the UPI app developer possesses. ${ }^{21}$

However, the RBI has mandated that the feature of interoperability be introduced for mobile wallets as well, albeit in a phased manner. Despite this direction by the $\mathrm{RBI}$, the promise of interoperability may not fructify in the manner as is envisioned by mobile wallet companies. This will be explained in the following part.

\section{Reserve Bank of India-Reservations on Mobile Wallets}

\subsection{RBI Master Direction dated 11 October 2017}

While the Master Direction is wide ranging and covers lot of matters, the following issues are significant from the perspective of this chapter:

(i) Interoperability to be permitted: The Master Direction requires that interoperability be introduced, albeit in a phased manner. First, with KYC-

\footnotetext{
${ }^{19}$ Ramanathan (n 10).

${ }^{20}$ Vindu Raj and Suhasini Raj, 'India Clings to Cash, Even as Tech Firms Push Digital Money' The New York Times (7 January 2018) <https://www.nytimes.com/2018/01/07/technology/indiadigital-money.html>.

${ }^{21}$ Although it should be noted that with the issuance of the most recent RBI circular dated 11 October 2017, PPI issuers such as mobile wallets would have to share any data with the RBI and 'any other agency/agencies as may be advised by RBI'. This has apparently been done to counter money laundering.
} 
compliant mobile wallets will be interoperable amongst themselves and subsequently, interoperability will be enabled between wallets and banks through UPI.

(ii) $\mathrm{KYC}$ norms to be strengthened: As a result of the new $\mathrm{KYC}$ norms, every mobile wallet user's supporting documents will be verified by an agency commissioned by the mobile wallet company. This has been viewed by many as sounding the death knell for mobile wallets, which already operate on wafer thin margins. ${ }^{22}$ The fear is that the customer acquisition cost will be too exorbitant. ${ }^{23}$ Essentially, it appears that whatever advantage the mobile wallets would have secured with interoperability has been squandered with the implementation of the stringent KYC rule. This would, in effect, amount to a re-acquisition of existing customers, many of whom might not want to go through the requirement of KYC.

(iii) Successive transactions are required to be authenticated with customer consent: Under the Master Direction, 'issuers shall introduce a system where every successive payment transactions in wallet is authenticated by explicit customer consent. ${ }^{24}$ This would apparently bring the mobile wallet at par with UPI apps which also requires a PIN for authentication of the transaction.

(iv) Capital requirements of Pre-Paid Instruments (PPI) issuers such as mobile wallets raised substantially: Under the revised Master Direction, non-bank entities must have a positive net worth of ₹ five Crores. Under the earlier RBI policy guidelines on PPIs, the minimum positive net worth was stipulated at ₹ one Crore. No reason has been attributed for this $400 \%$ increase in the minimum positive net worth requirement. Although it may be possible that by ensuring a higher net worth requirement, only serious players with a long-term vision for the sector will participate.

As mentioned above, certain changes in the RBI Master Direction render interoperability ineffective, since the mobile wallets may view the costs of conducting a KYC exercise as needlessly burdensome. Accordingly, the Master Direction may be viewed by mobile wallet companies as unfair and inequitable. ${ }^{25}$

\footnotetext{
${ }^{22}$ Goutam Das, 'The Money Revolution' Pressreader (4 June 2017). While merchants must pay a commission of approximately $1.8 \%$ to the mobile wallet company when there is a transaction, the mobile wallet company has to pay $1.5 \%$ service fee to the bank when money is debited from a bank account to a mobile wallet. Since users are not charged for anything, the business model of mobile wallet companies operates on a very low margin.

${ }^{23}$ Das (n 14).

${ }^{24}$ Master Direction, Clause 15.3 (c).

${ }^{25}$ However, even if the RBI has the power to prescribe guidelines on any issue falling within the purview of its mandate under the PSS Act, it should still ensure that the guidelines/circulars framed thereunder are not arbitrary and unreasonable. For instance, a perusal of the Master Direction makes it clear that the RBI has sought to regulate PPIs such as mobile wallets at par with bankswhether it is KYC norms/onerous capital requirements/authentication protocol. In doing so, the RBI is prescribing similar norms for both banks and mobile wallets despite the various differences that exist between the two and which have been alluded to above. Since the banks and PPIs do not
} 


\title{
4 European Commission and the Competition Commission of India_-Drawing Parallels
}

European Commission (EC) and European Parliament guidelines/briefing on interoperability. A 2012 Green Paper of the EC has recognized the need for interoperability among, inter alia, application developers and banks. ${ }^{26}$ A European Parliament Briefing on the consumer protection aspects of mobile payments reiterated the same in the following manner:

\begin{abstract}
As technology advances rapidly and options for mobile payment increase, lack of interoperability (including cross-border) between service providers is an issue. Better interoperability would provide consumers with more flexible payment options (better switching between different services and providers), leading to an increase in the number, speed and volume of mobile transactions. Better financial inclusion could be another benefit of more accessible and flexible services for consumers (also for the most vulnerable ones). Payments normally flow through the banking system, but mobile payments currently offer low regulatory entry barriers for new players, which could influence the payments markets, traditionally dominated by banks.
\end{abstract}

However, one needs to ask whether Competition Commission of India (CCI) should replicate the approach of EC. In this regard, it should be noted that a comparative assessment of the legislative scheme of Section 4 of the Competition Act 2002 and Article 102 of the Treaty for the Functioning of the European Union (TFEU) displays many similarities:

(a) Definition of 'dominant position'-Explanation (a) to Section 4 of the Act defines 'dominant position' as follows:

'Dominant position' means a position of strength, enjoyed by an enterprise, in the relevant market, in India, which enables it to -

(i) operate independently of the competitive forces prevailing in the relevant market; or

(ii) affect its competitors or the relevant market in its favor.

\footnotetext{
form a homogenous class, their similar treatment despite being dissimilar in their characteristics, amounts to unreasonable classification and may be treated as being ultra vires of Article 14 of the Constitution of India. Indeed, a former RBI deputy governor had remarked that 'if you don't insist on the same type of terms for banks and wallets, then there is clear arbitrage, and it is tantamount to picking a winner', further adding that 'if RBI doesn't lay terms of security and KYC, then wallets will be at a clear advantage.' This statement is reflective of bias that exists in favour of banks and may have led to the bracketing of banks and mobile wallets in a similar category-a categorization that may be unreasonable.

${ }^{26}$ 'The mobile payment market in Europe is still in its infancy. One of the main barriers to widespread take-up of m-payments seems to be a stalemate between Mobile Network Operators (MNOs), traditional PSPs (banks) and other players, such as manufacturers or application developers', Commission, Towards an Integrated European Market for Card, Internet and Mobile Payments COM (2011) 0941 final.
} 
This definition of 'dominant position' is derived from the European Court of Justice (ECJ $)^{27}$ decisions that have expounded on the concept of 'dominant position'. This is also mentioned (but not defined) in Article 102 of the TFEU. ${ }^{28}$

Elaborating upon the concept of 'dominant position', the ECJ judgements in the United Brands case ${ }^{29}$ and the Hoffman-LaRoche case ${ }^{30}$ say that dominant position is:

position of economic strength enjoyed by an undertaking which enables it to prevent effective competition being maintained on the relevant market by giving it the power to behave to an appreciable extent independently of its competitors, its customers and ultimately of the consumers. ${ }^{31}$

(b) Special responsibility on dominant enterprises-Section 4 of the Act is different from Section 3 in the sense that the proscribed conduct under Section 4 (2) is applicable only to dominant enterprises whereas the appreciable adverse effect on competition prohibited under Section 3 can be caused by any enterprise or enterprises.

This dichotomy between the two sections only serves to highlight the 'special responsibility' imposed upon a dominant enterprise to not to distort competition. Although, this special responsibility has not explicitly been mentioned in the Act, it can be inferred from the language of the Act as shown in the preceding paragraph. Indeed, the CCI recognized this 'special responsibility' while deciding the landmark $D L F$ case $^{32}$ in paragraph 12.20 of its Order. ${ }^{33}$ DLF argued $^{34}$ that the

\footnotetext{
${ }^{27}$ Presently called as Court of Justice of the European Union or CJEU.

${ }^{28}$ TFEU, art 102:

Any abuse by one or more undertakings of a dominant position within the internal market or in a substantial part of it shall be prohibited as incompatible with the internal market in so far as it may affect trade between Member States.
}

Such abuse may, in particular, consist in:

(a) directly or indirectly imposing unfair purchase or selling prices or other unfair trading conditions;

(b) limiting production, markets or technical development to the prejudice of consumers;

(c) applying dissimilar conditions to equivalent transactions with other trading parties, thereby placing them at a competitive disadvantage;

(d) making the conclusion of contracts subject to acceptance by the other parties of supplementary obligations which, by their nature or according to commercial usage, have no connection with the subject of such contracts.

${ }^{29}$ Case 27/76 United Brands v Commission of The European Communities (1978) ECLI:EU: C:1978:22.

${ }^{30}$ Case 85/76 Hoffmann-La Roche \& Co. AG v Commission (1979) ECLI:EU:C:1979:36.

${ }^{31}$ United Brands (n 29), para 65; ibid, para 38; OECD, 'Country Studies: European Commission-Peer Review Of Competition Law And Policy’ (2005).

${ }^{32}$ Belaire v DLF (2011) Competition Commission of India, Case No 19 of 2010.

${ }^{33}$ ibid.

${ }^{34}$ ibid, para 8.5 . 
conditions in the apartment buyer's agreement could not have been imposed due to abuse of dominant position since these were standard clauses in the majority of apartment buyer's agreement executed by any real estate developer and therefore, have been incorporated to meet the competition-something that is a defense as per the Explanation under Section 4(2)(a) of the Act. The CCI rejected this argument by saying that the responsibility of the dominant player is more onerous and similar practices by other developers would not fall within the ambit of Section 4.

In recognizing the concept of special responsibility, the CCI has taken a leaf out of the book of the ECJ in the Michelin case. ${ }^{35}$ The ECJ held that:

a finding that an undertaking has a dominant position is not in itself a recrimination but simply means that, irrespective of the reasons for which it has such a dominant position, the undertaking concerned has a special responsibility not to allow its conduct to impair genuine undistorted competition on the common market. ${ }^{36}$

The CCI's decision was confirmed by the Competition Appellate Tribunal (COMPAT) in its order as well where it reasoned that DLF, being 'a dominant player in the market, has a special duty to be within the four corners of the law'. ${ }^{37}$

The CCI had also reiterated its position on the special responsibility of the dominant enterprise in the Car Manufacturers Spare Parts case. ${ }^{38}$ It opined that the pro-competitive factors listed under Section 19(d)-Section 19(f) must be given less weightage than the anticompetitive factors under Section 19(a)-Section 19(c) when evaluating a vertical agreement by a dominant enterprise that forecloses the market. In doing so, it explicitly cited the Michelin case for the first time. ${ }^{39}$

Collective/Joint Dominance - Article 102 of the TFEU is not restricted to single firm conduct. ${ }^{40}$ The ECJ too recognizes the theory of collective/joint dominance under which several firms can share and abuse a dominant position. ${ }^{41}$

India too is seeking to introduce this concept by amending its competition legislation. The Competition (Amendment) Bill 2012 discusses the possibility of inserting language that would enshrine the concept of collective/joint dominance. It will do so by inserting 'jointly, or singly' after the word 'group' under Section 4(2). If it decides to do so, it will be following the lead of the EC. ${ }^{42}$

\footnotetext{
${ }^{35}$ Case 322/81 NV Nederlandsche v Commission of the European Communities (1983) ECLI:EU: C:1983:313.

${ }^{36}$ ibid, para 57.

${ }^{37}$ DLF v CCI (2014) COMPAT, W.P. (C) 6361/2014 and 6362/2014.

${ }^{38}$ Shamsher Kataria v Honda, Volkswagen, Fiat and Others (2011) Competition Commission of India, Case No. 03/2011.

${ }^{39}$ ibid, para 20.6.35.

${ }^{40}$ Any abuse by one or more undertakings of a dominant position.

${ }^{41}$ Case C-393/92 Municipality of Almelo and Others v EnergiebedrijfIJsselmij NV (1994) ECLI: EU:C:1994:171; Joined Cases T_68/89, T-77/89 and T-78/89 Italian Flat Glass Case (1992) Judgement of the court (First Chamber) ECLI:EU:T:1992:38.

${ }^{42}$ 'Collective dominance is a complex concept and is not widely used. In the European Union, it did not find place in the original legislation (The Treaty for the European Union or TFEU) but grew during the $1990 \mathrm{~s}$ through certain decisions of the courts. It has taken the courts several cases
} 
The Confederation of Indian Industry (CII) has however, voiced its concern over inserting under Section 4 since, Section 4 does not require the showing of an 'agreement' and therefore, the CCI would have unbridled discretion in determining what constitutes collective dominance. Not requiring the showing of an agreement might again put India in the same category as the EC since the judgement of the court (of the Fifth Chamber) had dispensed with the need to show an agreement in case of collective dominance. ${ }^{43}$ The court had held as follows:

The existence of a collective dominant position may therefore flow from the nature and terms of an agreement, from the way in which it is implemented and, consequently, from the links or factors which give rise to a connection between undertakings which result from it. Nevertheless, the existence of an agreement or of other links in law is not indispensable to a finding of a collective dominant position; such a finding may be based on other connecting factors and would depend on an economic assessment and, in particular, on an assessment of the structure of the market in question. ${ }^{44}$

Not required to show anticompetitive effect-Section 4 of the Act does not require a showing of an actual appreciable adverse effect on competition. Therefore, no competitive impact is required to be shown in case of abuse of dominance by an enterprise. This is similar to the position in the EC as well. To reach a finding of infringement, it is not necessary to show that the alleged abusive conduct produced an actual anticompetitive effect. It is enough to show that the conduct is likely to have or capable of having that effect. ${ }^{45}$

Predatory Pricing - The concept of predatory pricing has been mentioned in Section 4 of the Act. It is interesting to note that the language used in the act signifies that 'intent' has to be shown when alleging predatory pricing conduct by an enterprise. This is because the language used says it must be conducted 'with a view to reduce competition or eliminate the competitors' ${ }^{46}$ In such a case, it would not be dissimilar to the position espoused in some EC cases. In France Telecom SA $v$ Commission of the European Communities, ${ }^{47}$ the court reiterated its earlier stand in AKZO v Commission ${ }^{48}$ and Tetra Pak v Commission $^{49}$ when it said that prices

\footnotetext{
to progressively develop and clarify the concept, yet it is not frequently resorted to even in the EU', Vinod Dhall, 'Written submission to the Standing Committee on Finance', 15th Lok Sabha, Ministry of Corporate Affairs, The Competition (Amendment) Bill 2012, 83rd Report, para 35.

${ }^{43}$ Joined Cases C-395/96 P and C-396/96 P Compagnie v Dafra-Lines (2000) Judgement of the court (Fifth Chamber) ECLI:EU:C:2000:132.

${ }^{44}$ ibid, para 45 .

${ }^{45}$ United Brands (n 29).

${ }^{46}$ Explanation (c) to $\mathrm{s} 4$.

${ }^{47}$ Case C-202/07 P France Télécom SA v Commission of the European Communities (2009) Judgement of the court (First Chamber) ECLI:EU:C:2009:214.

${ }^{48}$ Case C-62/86 AK AKZO Chemie v Commission of the European Communities (1991) Judgement of the court (Fifth Chamber) ECLI:EU:C:1991:286.

${ }^{49}$ Case C-333/94 P Tetra Pak International SA $v$ Commission of the European Communities (1996) Judgement of the court (Fifth Chamber) ECLI: EU:C:1996:436.
} 
below average variable cost (AVC) are always considered abusive, but prices above AVC and below average total cost would require the showing of an intent to eliminate. ${ }^{50}$

Excessive Pricing - While the US has not come up with a definite standard for assessing excessive pricing cases, ${ }^{51}$ the TFEU does provide against the imposition of excessive prices. While 'excessive price' may not find a mention in Article 102 of the TFEU, it is generally understood to be covered by the prohibition under Article 102 (a) on charging 'unfair prices'. 52 This observation has been upheld by various judgements of the European Courts and EC as well. ${ }^{53}$

India too has tendered the notion that 'excessive price' is a subset of 'unfair price' in its written submissions to OECD Policy Roundtables on Excessive Pricing. ${ }^{54}$ Evidently, this is similar to the position taken in Europe. Again, like the EC law, the Indian Competition Act does not define 'unfair price'. Therefore, it is left to the CCI to interpret what constitutes unfair price. Perusing through the few cases that the CCI has adjudged on excessive pricing issues, it is heartening to note that the CCI has not decided to become a price regulator and intervene indiscriminately. The DIAL/MIAL case ${ }^{55}$ dealt with the allegation that DIAL/MIAL were charging excessive vehicle parking rates and the informant prayed that the rates be brought down by the CCI to the rates at the Kolkata/Chennai airports or the rates charged before privatization. The CCI refused to intervene, by holding that (a) there was competition at the time of bidding by consortia, (b) aeronautical services and non-aeronautical services cannot be looked into separately and (c) space should be ceded to the market forces of demand and supply in case of parking space, which is scarce at airports to begin with. Similarly, in the case of Manjit Singh Sachdeva v $D G C A,{ }^{56}$ the CCI (in response to a request by the informant to direct the Director General of Civil Aviation (DGCA) to fix a maximum retail price for airline tickets) said that the free market forces of demand and supply should govern the price.

\footnotetext{
${ }^{50}$ ibid, para 33.

${ }^{51}$ The FTC notes in its report that when the question was presented in court, judges have resorted to a case by case analysis and those decisions 'have not been particularly consistent'. It further states that given 'the uncertainty about what constitutes an unconscionable, excessive or exorbitant price, and the paucity of decisions on the issue, statutes based on any of these terms are likely to be difficult to enforce.'

Directorate for Financial and Enterprise Affairs Competition Committee, 'Working Party No. 2 on Competition and Regulation Excessive Prices- Background Paper' DAF/COMP/WP2 (2011)7/REV1 (9 January 2012) <http://www.oecd.org/regreform/sectors/49482277.pdf>.

${ }^{52}$ ibid.

${ }^{53}$ United Brands (n 29).

${ }^{54}$ Directorate for Financial and Enterprise Affairs (n 51).

${ }^{55}$ Citizen Grievances v Mumbai International Airport (2013) Competition Commission of India, Case No 51 of 2013.

${ }^{56} \mathrm{Mr}$ Manjit Singh Sachdeva v Directorate General of Civil Aviation (2012) Competition Commission of India, Case No 68/2012.
} 
This is similar to the outlook of the EC where cautious enforcement of antitrust laws is practiced, since it is seen as 'preferable to give market forces the time to play out and entry and expansion to take place, thereby bringing prices back to more normal levels'. ${ }^{57}$ Therefore, from the above, it appears that the legislative scheme of the Act is significantly influenced by the jurisprudence of the EC on antitrust law. All this is significant as we proceed to examine whether the antitrust law doctrine of Essential Facilities originating in the EC can find resonance in the payments market in India.

\section{The Essential Facilities Doctrine}

Before commencing with a discussion on the Essential Facilities Doctrine (EFD), it is important to consider a few hypothetical situations. Considering how significant interoperability is to the future of mobile wallets-what if the RBI Master Direction was to be implemented in its current form? As mentioned earlier, the addition of regulations pertaining to KYC norms, capital requirements and authentication would probably be a disincentive for mobile wallets and certainly takes away whatever benefit the mobile wallets would have derived from interoperability. However, what if, theoretically speaking, these other regulations were struck down by a court or withdrawn by the RBI? Would interoperability still be extended to mobile wallets? If it was extended, what if the banks still refused to provide the Application Programming Interface (API) required for interoperability? In such a scenario, and most significantly, could the EFD be invoked by mobile wallets to secure access to such API?

Assuming that banks refuse the API, how would the EFD be invoked by the mobile wallets? Before answering these questions, it is necessary to understand the origins of the EFD and the decisional practice concerning the doctrine followed by the EC.

Practice of the EC in EFD cases are:

(a) Commercial Solvents case ${ }^{58}$ : Commercial Solvents Corporation (CSC) was the parent company of Istituto, a company incorporated under Italian law. Istituto was the reseller of aminobutanol, which was an intermediary product for the manufacture of ethambutol and ethambutol-based specialties, used as an anti-tuberculosis drug. Zoja Istituto's customer also used the aminobutanol for the manufacture of ethambutol-based specialties. In 1970, CSC stopped supplying aminobutanol to the European Union. At the end of 1970, when Zoja

\footnotetext{
${ }^{57}$ Directorate for Financial and Enterprise Affairs Competition Committee, 'Policy Roundtables: Excessive Prices' DAF/COMP(2011)18 (7 February 2012) <http://www.oecd.org/competition/ abuse/49604207.pdf>.

${ }^{58} \mathrm{C}$ 6-7/73 Commercial Solvents v Commission (1974) Court of Justice of European Union ECLI: EU:C:1974:18.
} 
placed a new order for aminobutanol, CSC responded that there is no availability of the same. It also happened to be the case that CSC was the only possible source of aminobutanol in the world market. Zoja moved the EC for institution of proceedings against CSC. The EC decided to require CSC to supply, inter alia, $30,000 \mathrm{~kg}$ of aminobutanol to Zoja. CSC challenged this aforementioned EC order before the ECJ. The EC's stance was that 'discontinuance of the supply of aminobutanol had the effect that Zoja was forced to discontinue its manufacturing process and to become a mere packer and distributor of ethambutol. ${ }^{59}$ The ECJ observed that the fact Zoja had survived so far does not alter the fact that Zoja had disappeared from the market as a manufacturer of ethambutol.

One of the justifications advanced by CSC in cutting back the sale of aminobutanol and other raw materials required to make ethambutol was that it had been CSC's longstanding policy to come into closer connection with the end user and therefore decided to have more raw materials available for itself to make sales of the final derivative product. ${ }^{60}$

However, the ECJ found the same conduct to be abusive. ${ }^{61}$ It remarked as follows:

It follows that an undertaking which has a dominant position in the market in raw materials and which, with the object of reserving such raw material for manufacturing its own derivatives, refuses to supply a customer, which is itself a manufacturer of these derivatives, and therefore risks eliminating all competition on the part of this customer, is abusing its dominant position. ${ }^{62}$

(b) Magill case ${ }^{63}$ : RTE and ITP, two broadcasters, had a stringent policy regarding dissemination of programme listings wherein only daily listings were to be provided to daily and periodical newspapers. When Magill attempted to publish

\footnotetext{
${ }^{59}$ ibid.

${ }^{60}$ Commercial Solvents (n 58).

${ }^{61}$ It should be noted however, by forcing CSC to supply aminobutanol to Zoja in complete disregard of its longstanding policy to establish a direct connection with the end user would raise the following issue:

Duty to shareholders v Duty to competitors: The directors of a company which controls or maintains hold over a key raw material, may find themselves in a quandary when deciding whether to supply such raw materials to others. One argument could be that the EFD would mandate they should supply it. However, Section 166 of the Companies Act 2013 which prescribes the duties of directors mentions, inter alia, that a director of a company shall act in good faith in order to promote the objects of the company for the benefit of its members as a whole, and in the best interests of the company, its employees, the shareholders, the community and for the protection of environment. Which duty would prevail? The duty to supply to others in the market? Or the duty to look out for the best interests of shareholders and act in the best interests of the company?

${ }^{62}$ Commercial Solvents (n 58).

${ }^{63} \mathrm{C}-241 / 91$ and C-242/91 Radio TelefisEireann v Commission (1995) Court of Justice of European Union ECLI:EU:C:1995:98.
} 
a weekly TV guide, it was prevented from doing so by both RTE and ITP. Magill approached the Commission to seek a ruling that both RTE and ITP were abusing their dominant position by refusing to grant licenses for publication of their weekly TV listings. The EC found a breach and ordered the defendants to supply to third parties on request, on a non-discriminatory basis with their individual advance weekly programme listings for the purpose of publication. The Court of First Instance (CFI) affirmed the decision of the EC. The CFI held that the third parties like Magill were in a position of 'economic dependence' on parties like RTE and ITP. The CFI also held that while copyright entitled the copyright holder to reserve the exclusive right to reproduce the protected work, it was apparent that the right was being exercised in such ways so as to pursue an aim manifestly contrary to objectives of Article 86 of the Treaty Establishing the European Economic Community (EEC Treaty). ${ }^{64}$ CFI noted that by reserving the exclusive right to reproduce their weekly listings, RTE and ITP were 'preventing the emergence on the market of a new product, namely a general television magazine likely to compete with their own magazines'. ${ }^{65}$ This, as per the CFI, 'went beyond what was necessary to fulfill the essential function of the copyright'. 66

Before the ECJ, ITP submitted that:

copyright owners ordinarily and naturally exercise their copyright in order to restrict competition with their own product by other products made using their copyright material, even on a derived market. That, it continues, is the essence of copyright. RTE further added that the owner of an intellectual property right is under no obligation to offer justification for his refusal to grant a license. ${ }^{67}$

The ECJ found the conduct abusive, owing to the following reasons:

(i) Preventing appearance of new product: Both RTE and ITP's refusal to provide basic information prevented the appearance of a new product for which there was potential consumer demand.

\footnotetext{
${ }^{64}$ EEC Treaty, art 86:

Any abuse by one or more undertakings of a dominant position within the common market or in a substantial part of it shall be prohibited as incompatible with the common market insofar as it may affect trade between Member States.

Such abuse may, in particular, consist in:

(a) directly or indirectly imposing unfair purchase or selling prices or other unfair trading conditions;

(b) limiting production, markets or technical development to the prejudice of consumers;

(c) applying dissimilar conditions to equivalent transactions with other trading parties, thereby placing them at a competitive disadvantage;

(d) making the conclusion of contracts subject to acceptance by the other parties of supplementary obligations which, by their nature or according to commercial usage, have no connection with the subject of such contracts.

${ }^{65}$ Radio TelefisEireann (n 63), para 29.

${ }^{66}$ ibid, para 30.

${ }^{67}$ ibid, para 39.
} 
(ii) No justification: There was no justification for such refusal either in the activity of television broadcasting or in that of publishing television magazines.

(iii) Excluded all competition: The parties, by their conduct reserved to themselves the secondary market of weekly television guides by excluding all competition on that market.

(iv) Indispensability: The parties denied basic information which is the raw material indispensable for the compilation of such a guide.

It should be noted that the ECJ did not, at any stage, anywhere in its judgement expound the EFD or list its constituent elements.

(c) Bronner case ${ }^{68}$ : In this case, a regional court in Vienna, referred to the ECJ for a preliminary ruling on the interpretation of Article 86 of the EEC Treaty. The facts involved Oscar Bronner, a company editing, publishing, manufacturing and distributing the daily newspaper Der Standard. Mediaprint published more prominent newspapers and has established a nationwide home-delivery scheme for the distribution of its newspapers. Oscar Bronner sought an order mandating Mediaprint to include its Der Standard newspaper in its home delivery scheme because its own mode of distribution (which involved postal delivery) did not take place until late morning whereas Mediaprint's home delivery scheme delivered in the early hours of the morning. Oscar Bronner referred to the EFD, as established in the Magill case and made it clear that by owning the only 'economically viable' home-delivery scheme in Austria, Mediaprint is obliged to allow access to the scheme by competing products. ${ }^{69}$

Mediaprint objected first by submitting that 'undertakings in a dominant position are also entitled to the freedom to arrange their own affairs, in that they are normally entitled to decide freely to whom they wish to offer their services and, in particular, to whom they wish to allow access to their own facilities. ${ }^{70}$ Mediaprint also submitted that 'all competition' was not eliminated as Bronner had other distribution systems which could enable it to sell its papers in Austria. $^{71}$

The ECJ proceeded by observing that it would be necessary:

for the Magill judgement to be effectively relied upon in order to plead the existence of an abuse...,not only that the refusal of service comprised in home-delivery be likely to eliminate all competition in the daily newspaper market on the part of the person requesting the service and that such refusal be incapable of being objectively justified, but also that the

\footnotetext{
${ }^{68}$ Case C-7/97 Oscar Bronner v MediaprintZeitungs (1998) Court of Justice of the European Union ECLI:EU:C:1998:569.

${ }^{69}$ ibid, para 24.

${ }^{70}$ ibid, para 26.

${ }^{71}$ ibid, para 27.
} 
service in itself is indispensable to carrying on that person's business, inasmuch as there is not actual or potential substitute in existence for that home-delivery scheme. ${ }^{72}$

The ECJ went on to observe that there were other methods of distributing newspapers even though they may be less advantageous and that it is not enough to argue that such other systems are not economically viable by reason of small circulation. Accordingly, the ECJ found the conduct of Mediaprint to not constitute an abuse of its dominant position. ${ }^{73}$

(d) IMS Health case ${ }^{74}$ : Both IMS and NDC were entities that were engaged in tracking the sales of pharmaceutical and healthcare products. IMS provided data on regional sales of pharmaceutical products in Germany to pharmaceutical laboratories by using a brick structure. ${ }^{75}$ The IMS brick structure comprised of 1,860 bricks or a derived structure consisting of 2,847 bricks. NDC acquired a company PII that had also decided to use brick structures of 1,860 or 3,000 bricks, 'very similar to those used by IMS ${ }^{76}$ An interlocutory order was granted prohibiting PII from using the aforesaid brick structure. NDC complained to the EC and eventually, the EC adopted an interim measure ordering IMS to grant a license to all undertakings present on the market for provision of German regional sales data. The EC held that the IMS brick structure had become the industry standard and refusal of access without any objective justification would eliminate all competition. Eventually the EC order was withdrawn since there was no urgency anymore in imposing interim measures. Therefore, the court before whom the main proceedings (from where the issue originated) were ongoing had requested the ECJ's preliminary ruling regarding interpretation of a key question, namely, whether the refusal to grant a license to use a brick structure constitutes an abuse of dominant position.

IMS argued, inter alia, that the refusal to grant a license must prevent the emergence of a new product (along with other factors which need to be proved). Since NDC intends to use the same brick structure as IMS, it cannot be said to introduce a new product on the market and was instead, supplying the same product in the same market. ${ }^{77} \mathrm{NDC}$ however claimed that it is not essential for there to be two distinct markets. ${ }^{78}$ However, the ECJ observed that as per the Bronner judgement, it was held that it was relevant to distinguish an upstream market

\footnotetext{
${ }^{72}$ ibid, para 41.

${ }^{73}$ ibid, para 45.

${ }^{74}$ Case C-418/01 IMS Health v NDC Health (2004) Court of Justice of the European Union ECLI: EU:C:2004:257.

${ }^{75} \mathrm{~A}$ brick structure is a data collection system which segregates geographical regions into 'bricks' comprising of few pharmacies each. The structure is used to track and subsequently, used by pharmaceutical companies to analyse their sales strategies.

${ }^{76}$ IMS Health (n 74).

${ }^{77}$ ibid, para 32.

${ }^{78}$ ibid, para 33.
} 
constituted by the product in question and a downstream market, on which the product in question would be used to create a derivate product. Therefore, the ECJ held that the refusal to grant a license may be abusive only where the entity requesting the license does not reduce itself to merely duplicating the product in question, 'but intends to produce new goods, not offered by the owner of the right and for which there is potential consumer demand' ${ }^{79}$

(e) Microsoft case ${ }^{80}$ : The EC found Microsoft guilty of abusing its dominant position with respect to two types of conduct. The first abusive conduct related to Microsoft's refusal to supply its competitors with 'interoperability information' which could be used for the purpose of developing and distributing products competing with Microsoft's own products on the work group server operating systems market. The second abusive conduct pertained to Microsoft making its operating system available contingent on the simultaneous acquisition of the Windows Media Player software.

For this chapter, authors have focussed only on the first abuse, namely, Microsoft's refusal to supply interoperability information to its rivals for developing new products. This is being done since the second abuse concerns a practice commonly known as 'bundling' (where products are not available on a standalone basis and are instead sold only in a bundle with each other). The present imbroglio with mobile wallets and interoperability does not involve the issue of bundling.

Microsoft started by invoking an assortment of intellectual property rights (IPRs) for protecting its interoperability information protocol such as those granted under patent law, copyright law and trade secrets law. The CFI remarked that the central issue in this case would be whether the conditions under which a dominant entity may be required to grant a license to its intellectual property (IP) are satisfied in the instant case. Below is a brief summary of the court's findings on the four ingredients of the EFD:

(i) Indispensability: Microsoft submitted that a particular technology could not be indispensable if it was 'economically viable' for the competitors to develop and market their products without access to that technology. Further, Microsoft claimed that the EC failed to show a causal link between the non-availability interoperability protocol and the claimed inability of the competitors to compete. ${ }^{81}$ The EC replied by stating that the Microsoft's view on indispensability would tantamount to an 'inefficient interoperability solution' that would allow competitors to achieve only de minimis market penetration whereas what is needed was an 'economically viable source'. ${ }^{82}$

\footnotetext{
${ }^{79}$ ibid, para 49.

${ }^{80}$ Case T-201/04 Microsoft v Commission (2017) Judgement of the Court of First Instance ECLI: EU:T:2007:289.

${ }^{81}$ ibid, para 341 .

${ }^{82}$ ibid, para 355 .
} 
The CFI rejected Microsoft's submissions and was able to establish a causal link between the denial of the interoperability protocol and the receding market share of its competitors. However, the CFI also held that indispensability also required that the degree of interoperability should be such that "non-Microsoft work group server operating systems must be capable of interoperating with the Windows domain architecture on an equal footing with Windows work group server operating systems if they were to be marketed viably on the market. ${ }^{83}$

(ii) Elimination of competition: Microsoft submitted that the EC referred to a 'mere risk of elimination of competition in the market', when the refusal in question should instead be likely to eliminate all competition. Therefore, the standard adopted, as per Microsoft, should be 'something close to certainty. ${ }^{, 84}$ The CFI however, held as follows:

Nor is it necessary to demonstrate that all competition on the market would be eliminated. What matters, for the purpose of establishing an infringement of Article $82 \mathrm{EC}$, is that the refusal at issue is liable to, or is likely to, eliminate all effective competition on the market. It must be made clear that the fact that the competitors of the dominant undertaking retain a marginal presence in certain niches on the market cannot suffice to substantiate the existence of such competition. $^{85}$ (emphasis added)

Therefore, what was required to be demonstrated was not the elimination of 'all competition' but only 'all effective competition'.

(iii) New product: Microsoft submitted that the EC order failed to point out any new product that would be developed as a result of providing the interoperability protocol. All that would be accomplished is the creation by the competitors of an enhanced version of Microsoft's own product. And that, it was claimed by Microsoft, amounts to merely an addition of a feature that cannot be viewed as the creation of a 'new product'. ${ }^{86}$

The CFI held that the appearance of a new product cannot be the only parameter to judge whether the refusal in question is abusive. Such abusive conduct may also be established by limiting technical development as well. ${ }^{87}$ The CFI contemplated that the competitors would have no reason to imitate Microsoft's product since in order to 'maintain a profitable presence in the market', the competitors would have choice other than 'to differentiate their products from Microsoft's products with respect to certain parameters and certain features, ${ }^{88}$

\footnotetext{
${ }^{83}$ ibid, para 421.

${ }^{84}$ ibid, para 439.

${ }^{85}$ ibid, para 563.

${ }^{86}$ ibid, para 626.

${ }^{87}$ ibid, para 647.

${ }^{88}$ ibid, para 668.
} 
(iv) Objective Justification: Microsoft again invoked its IPRs as a justification for refusing to supply the protocol in question. In addition, Microsoft claimed that providing a license to the competitors would also have a negative impact on the incentives to innovate. The EC however, countered by saying that the 'positive impact on the level of innovation in the whole industry outweighed the negative impact of the dominant undertaking's incentives to innovate.' The CFI concurred with the EC and held that it was normal practice in the industry for operators to disclose to third parties information that enables interoperability and such disclosure cannot have any negative impact on the incentives to innovate. ${ }^{89}$ Accordingly, the CFI ruled that Microsoft had not shown any objective justification while refusing to disclose its interoperability protocol.

\subsection{Essential Facilities Doctrine in India}

CCI's prior jurisprudence on the issue of EFD is scant. ${ }^{90}$ The NSE case had involved the issue of an essential facility. ${ }^{91}$ Eventually the CCI did not rule on whether the Application Program Interface Code (APIC) was an essential facility. ${ }^{92}$ Further, when the matter went on appeal to the erstwhile COMPAT, the COMPAT did not rule on the issue as the parties had reached a settlement on the APIC issue. ${ }^{93}$

\footnotetext{
${ }^{89}$ ibid, para 702 .

${ }^{90}$ MCX Stock Exchange v National Stock Exchange (2009) Competition Commission of India, Case No 13/2009; one of the issues that was raised by MCX-SE was the denial of a market watch facility that was offered by NSE.

${ }^{91}$ The CCI noted that 'NSE had acquired a $26 \%$ stake in Omnesys which was a technology vendor providing software for financial and securities market. The stake was taken through DotEx a 100\% subsidiary of NSE. DotEx/Omnesys created a new product known as 'NOW' which was intended to substitute software called "ODIN" developed by FTIL (the promoters of MCX-SE). NSE simultaneously refused to share its Currency Derivatives segment Application Programme Interface Code (APIC) with FTIL thus disabling the users of ODIN from connecting to the market watch of NSE's CD segment trade. APIC, it was argued by MCX-SE, was an essential facility to connect front end application of NOW with any other application such as ODIN, which constitutes the electronic trading platform of the stock exchanges', ibid.

${ }^{92}$ But the CCI did rule that 'normally, APIC should have been denied for all segments but this was not the case', and the denial of this facility to MCX-SE smacked of anticompetitive intent. This, it would appear, seems to suggest that the Commission felt that the feasibility of providing the facility was not in doubt, ibid.

${ }^{93}$ The COMPAT held that 'as regards exclusionary denial of integrated market watch facility, we need not express anything here .... in view of settlement of the concerned parties', The National Stock Exchange of India v Competition Commission of India (2014) COMPAT, Appeal No 15 of 2011 with IA NoS 25/2011, 26/2011, 27/2011, 10/2012,27/2012.
} 
However, when reference is made to other governmental reports, it becomes clear that EFD has been considered in the Indian context as well. For instance, a review of the Report of the Working Group on Competition Policy constituted by the erstwhile Planning Commission, exhibits traces of the EFD. The aforesaid report, in fact, considered the EFD as one of the guiding principles of a national competition policy. ${ }^{94}$ Similarly, the Draft Competition Policy 2011 prepared by the Committee on National Competition Policy (that was constituted by the Ministry of Corporate Affairs) also saw to it that a national competition policy, when drafted, should also include 'third party access to essential facilities' as one of the principles. $^{95}$

Therefore, the concept of 'essential facilities' does find mention in various governmental reports and is not altogether an alien concept to India's competition law experts. However, it still lacks a legislative framework and any kind of decisional practice that would lay out the contours of how such doctrine is to be applied.

However, a recent CCI prima facie Order under Section 26(1) of the Competition Act 2002, appears to have veered close to recognizing the EFD. In HPCL-Mittal Pipelines Limited (HMPL) v Gujarat Energy Transmission Corporation Limited (GETCO) and Ors. ${ }^{96}$, the CCI found the conduct of GETCO and other Opposite Parties (OPs) as anticompetitive at prima facie level. The Informant, HMPL, had alleged that the denial of open access to electricity by the OPs to itself was not in consonance with the principle of open access that was envisioned under the Electricity Act 2003 (which sought to create an environment where the power generating companies could sell power to the highest bidder and consumers could buy power from the most economical source instead of purchasing power from the distribution licensee). Therefore, it was alleged that by denying HMPL the right to link to a distribution company of its choice, the OPs had, inter alia, denied market access to other distribution companies that may have been able to supply to HMPL, were it not for the refusal of the OPs to provide it with a no objection certificate (NOC) and permission to source power from other distribution companies. While the CCI refrained from using the term 'EFD' in its prima facie order, the essential conditions for the invocation of the doctrine appear to be there. Firstly, the NOC was indispensable as HMPL could not have itself constructed a power generation facility to source power from. Secondly, there would be a killing of 'effective competition' by the OPs since by refusing to provide the requisite permission, it would damage the commercial prospects of HMPL, which actually

\footnotetext{
${ }^{94}$ 'Control over essential facilities by dominant enterprises undermines competition by denying access to new entrants. Third party access to essential facilities on reasonable fair terms will ensure effective competition and, therefore, should be provided in law. However, what constitutes an essential facility may differ on a case to case basis', Planning Commission, Government of India, 'Report Of The Working Group on Competition Policy' (February 2007), para 5.2.1 <http:// planningcommission.nic.in/aboutus/committee/wrkgrp11/wg11_cpolicy.pdf>.

${ }^{95}$ 'Draft National Competition Policy' (2011), para $7.1<$ http://www.mca.gov.in/Ministry/pdf/ Draft_National_Competition_Policy.pdf>.

${ }^{96}$ HPCL v Gujarat Energy (2017) Competition Commission of India, Case No 39 of 2017.
} 
competed with OP two in the instant case (which was a wholly owned subsidiary of GETCO). Thirdly, the denial of permission by GETCO and other OPs would restrain the technical development of the product as well. Indeed, the CCI found that the OPs had violated Section 4(2)(b)(i) and limited technical development. Lastly, the Commission also found that there was no objective justification offered by the OPs in refusing an NOC or permission to HMPL since their grounds of network constraints were found to be illegitimate.

Notwithstanding the above case, the authors will briefly examine below how the mobile wallet companies may embark on securing the API of the interoperability protocol of UPI, should it be denied by the banks.

To highlight the same, each ingredient of the EFD will be discussed. Such discussion will be informed by jurisprudence of the EC/ECJ/CFI that had been underscored earlier. Further, the discussion will also take into account the potential pitfalls as well as opportunities arising from such jurisprudence from the perspective of mobile wallet companies, when invoking the EFD.

(i) Indispensability: While the Commercial Solvents case had laid down the criteria that would have to be cumulatively satisfied to successfully invoke the EFD, it remained silent on how each ingredient was to be applied. The Magill case, on the other hand, is the first case that had attempted to explain, inter alia, how indispensability would be assessed. During its judgement, the ECJ was of the opinion that Magill, as a publisher of a weekly TV guide was in a position of 'economic dependence' on news channels such as RTE and ITP. However, it is debatable whether Magill could really be said to be dependent on those channels when they comprise only a tiny proportion of the total number of channels for which the guide would be published. Taking this argument further, can an applicant entity said to be economically dependent on a dominant entity when the item that is sought to be procured from the dominant entity would constitute only a fraction of the applicant entity's revenues?

The Bronner case further narrowed the scope of how indispensability was to be construed. It effectively held that a facility is not indispensable if there are other methods to develop the facility available at the disposal of the applicant entity, even though if these methods are less advantageous and not economically viable.

The Microsoft case however, reversed the reasoning of the Bronner case. In the Microsoft case, the CFI has diluted the indispensability requirement defined in the earlier cases by insinuating that even though the applicant entity requesting the 'essential facility' may be able to create an interoperability protocol on its own, however, if the protocol so created was not marketable or commercially viable, then the enterprise could always fall back on the EFD to secure it from the entity holding the predominant interoperability protocol.

From the above, it appears that if the mobile wallet companies were to go by any measure of the indispensability requirement as defined over the years by the ECJ/ CFI, it would have a strong argument to secure access to the API of the banks. Firstly, mobile wallets companies appear to be in a position of economic 
dependence on the banks as the refusal by banks to provide the API could scuttle their chances to be truly interoperable with other mobile wallets and the banks. This would have a concomitant impact on their commercial viability, a key element when appraising indispensability, since the interoperability feature would not be there.

(ii) Eliminate competition: The promising growth of mobile wallets (albeit it may have plateaued in terms of the value of transactions compared to UPI apps), even in the absence of interoperability, may prove at the very outset that a lack of interoperability would not kill all competition. However, given that the Microsoft case has effectively shifted the goalposts on what 'competition' means, it can still be asserted that mobile wallet companies would be able to satisfy this criterion as well. The Microsoft case saw the CFI ruling that the refusal to provide the essential facility does not have to result in hindering the emergence of all competition, but only all effective competition. In other words, even if the refusal does not prevent the applicant entity from being able to compete in some manner with the dominant entity, that alone would not disqualify the applicant entity from invoking the EFD.

Accordingly, one may argue that it is not a prerequisite for mobile wallet companies to show an irreversible decline of their business prospects if they were not to be provided with the interoperability protocol. Instead, the fact that a denial will blunt their ability to compete effectively with UPI apps will be sufficient reason to provide them with the claimed protocol.

(iii) New Product: While the IMS Health case had categorically said that the creator of the new product must offer a product that is not offered by the owner of the right, the Microsoft case again, diluted what could be considered as a new product. In fact, the Microsoft case held that it is not even necessary for there to be a new product. It is sufficient if the refusal results in the limitation of technical development. The mobile wallet companies would face a hard time furnishing any meaningful evidence regarding the creation of a new product as most banks would also have a mobile wallet. However, the fact that a refusal would prevent the addition of new features into an existing mobile wallet would definitely fall within the purview of restricting technical development.

(iv) Objective justification: While a refusal to provide an essential facility may be justified by some entities on grounds of scarcity of raw material, the same would not be a justifiable reason in the present case of mobile wallets. Since the supply of API is non-rivalrous in nature, (i.e., one mobile wallet's use of the bank's API does not come at the expense of any other mobile wallet or bank), it is feasible to supply it as it is readily available. The API is merely a tool for building a software, and stipulates how various software components interact with one another. The same is therefore a proprietary product that can be lent to more than one mobile wallet company at any given time. 


\subsection{Evaluation Under Section 4 of the Act}

Since the EFD is applicable only to dominant enterprises, it would have to be examined whether the conduct of banks would be that of a dominant entity under Section 4 of the Act.

(i) Whether CCI has jurisdiction: This pertains to an issue of probable regulatory conflict of the CCI with the Copyright Board under the Copyright Act which has been discussed later in this chapter.

(ii) Enterprise concerned: It appears that the relevant entity for the purposes of evaluating dominance would be a bank, since it the bank that possesses the API. However, for the sake of a comprehensive academic analysis, authors have elaborated on the other side of the argument as well. Some may submit that it is the NPCI which is the relevant enterprise since it was the NPCI that had introduced the concept of UPI and also has a UPI app of its ownBHIM. Unlike other UPI apps that are connected or linked to a particular bank, BHIM was mandated to be integrated with the software applications of all banks that comprised the NPCI, thus giving it a unique status among other UPI apps. ${ }^{97}$ However, it would appear that since the NPCI itself does not have any API to offer, there cannot be an issue of refusal or denial of providing API in the first place. Therefore, the definition of 'enterprise' is more likely to include only a bank. Since it is the bank which actually provides the API of the interoperability and therefore is in a position to refuse or deny access to such API, the appropriate enterprise for the purpose of the evaluation would appear to be the banks.

(iii) Whether API is a good or service: Since the present case involves the issue of licensing the right to use the interoperability protocol, the question is whether the same can be regarded as a 'good' or 'service'. It should however, be noted that Section 2(u) of the Act does define 'service' to include a 'service of any description which is made available to potential users and includes the provision of services in connection with business of any industrial or commercial matters such as banking...'. Since the API in question has no utility unless it is provided to enable interoperability (and in most cases, the banks provide the API to third party UPI app developers to enable interoperability), it would fall within the purview of a 'service which is made available to potential users...in connection.....with banking'.

(iv) Relevant market: As per Section 2(t) of the Act, the 'relevant product market' means all those products or services which are regarded as interchangeable or substitutable by the consumer, by reason of characteristics of the products or services, their prices and intended use. At first glance, one may be tempted to delineate the relevant market as the "provision of banking services' considering that the issue in question involves banks. However,

\footnotetext{
${ }^{97}$ Ramanathan (n 7).
} 
since the contentious point here is the potential denial of the API by banks to mobile wallet companies, the relevant product market should instead be the 'provision of API of the interoperability protocol by all banks to mobile wallets'. It should be pointed out here for the sake of a complete and informed analysis that the relevant product market cannot be limited to the provision of API of interoperability protocol by each bank. This is due to the fact that just as there is no limitation here on the owner of a primary product (a bank account) to switch to the secondary product (a UPI app) of another bank, similarly, each mobile wallet company has to secure just one API from a bank to secure interoperability. For instance, ICICI Bank can easily provide an API to a mobile wallet company that would make its mobile wallet interoperable with all other mobile wallets. Even though each API is unique in itself, the fact is that for a mobile wallet company, the choice of bank that actually provides the API would not matter. Therefore, the relevant market could be the 'provision of API of the interoperability protocol by all banks to mobile wallets'. Alternatively, however, if a mobile wallet company chooses to tie up with a bank for offering certain banking services, like many UPI app developers have done, then the choice of the bank as the API provider would matter owing to each bank's unique suite of banking services ${ }^{98}$ and accordingly it may not be possible to contend that the relevant product market would comprise of provision of API of interoperability protocol of all banks.

(v) Dominance: Each API is unique to the bank which provides it, but when taken collectively, no single bank could be said to be dominant in the relevant market. Since the concept of collective dominance has not been introduced under the Act, it may not be possible to invoke the essential facilities doctrine with no dominance being established. However, under the alternative definition of relevant product market provided above, it is possible that each bank is considered as dominant in the provision of its unique API to a mobile wallet company.

\subsection{Possible Grounds for a Refusal by Banks}

Firstly, since the API is an internal program that is not available for sale in the open market, can antitrust authorities compel companies to divert what would otherwise be captive production (to be used for internal consumption)? In vertically integrated groups, it is common for the upstream arm to produce only internally for 'captive

\footnotetext{
${ }^{98}$ It should be remembered that any UPI app is, after all, an app that is tied to a particular bank. While the fact that each UPI app is platform agnostic is a great attraction, at the end of the day, a lot of users would also want to transact on that particular app owing to the bank (that has tied up with the app) offering some unique boutique of services.
} 
use' by the downstream arm. The issue is whether such 'captive production' by the upstream arm should be included in product market or whether such product market should only include those products that are sold in the 'merchant market'. For instance, in Pfizer/Hospira (C-2015/03/255), when analyzing the possibility of vertical foreclosure due to Pfizer selling formulations and Hospira selling APIs (Active Pharmaceutical Ingredients), it was observed that Hospira was primarily utilizing the APIs for internal use and not for sale in the merchant market and therefore there was no possibility of foreclosure of input foreclosure as the API could not be considered an input. Similarly, in Aditya Birla Chemicals/Grasim, the combined market was calculated by excluding any production that was captively consumed. However, these are combination cases and the Commission may adopt a different approach when evaluating the same under the antitrust regime dealt with by Section 4 .

Secondly, since the interoperability protocol API is likely protected as a trade secret or copyright, it may be difficult to secure access to it. The recent White Paper of the Committee on Experts on a Data Protection Framework for India also recognized that it may be difficult to compel businesses to provide access to their algorithms that are used to make automated decisions as this right to access is likely to be heavily limited owing to trade secrets of these businesses. ${ }^{99}$

Thirdly, it would appear natural that the courts will not second guess the value judgement or the business acumen of private enterprises.

Since this chapter is concerned with the interface between IP and antitrust law, it will now focus on the second ground of IP protection.

\section{Intellectual Property Defense}

Section 3(5)(i) of the Competition Act 2002 provides that nothing in Section 3 shall restrict the right of any person to restrain any infringement of, or to impose reasonable conditions, as may be necessary for protecting their IPRs. The CCI has dealt with the issue of IPRs in a few cases.

In the FICCI Multiplex case, ${ }^{100}$ the first cartel case decided by the CCI, one of the arguments adopted by the arraigned parties before the CCI in order to justify not providing access of their films to multiplex owners was that 'no multiplex owner can demand that the film be released in a theatre let alone dictate the commercial terms on which such film must be released.' ${ }^{101}$ This, it was argued, was due to the

\footnotetext{
99، White Paper of The Committee of Experts on a Data Protection Framework for India' (2017) <http:// meity.gov.in/writereaddata/files/white_paper_on_data_protection_in_india_171127_final_v2.pdf>.

${ }^{100}$ FICCI-Multiplex Association v United Producers (2009) Competition Commission of India, Case No 01 OF 2009.

${ }^{101}$ ibid, para 23.11.
} 
copyright that subsisted in the films which gave them the right to decide on what terms to provide the films. The CCI held that copyright is a statutory right and not an absolute right and would be subject to the rigors of the Competition Act 2002. In the Shamsher Kataria case ${ }^{102}$ on the other hand, the CCI emphasized that the party in question may 'impose reasonable conditions, as may be necessary for protection any of his rights'. In the view of the CCI, the concept of protection of an IPR was qualified by the word 'necessary'. So the key question for consideration by the CCI in such cases was viewed to be: whether the IPR holder can protect his IPR, even if such restriction was not present. In the instant case, the CCI held that the restrictions that had been imposed by certain car manufacturers on the sale of their spare parts to everyone except their own subsidiaries, was beyond the scope of what was considered as necessary in order to protect the IPR that was vested therein.

However, it is pertinent to note that the IP defense is only available to agreements that are coming under the purview of Section 3 of the Act. In other words, there is no such defense available for abuse of dominance. However, since the EFD does not squarely fall under any of the provisions of the abuses listed under Section 4 of the Act, perhaps IP protection can be invoked. In such a case, it might come down to an issue of conflict between different statutes, i.e. The Copyright Act 1957 and the Competition Act 2002.

In this regard, it is noted that the Copyright Act is a statute that deals with consolidation of the law relating to copyright in India, but is not a comprehensive piece of legislation in that it does not cover anticompetitive conduct that may result (as a result of copyright subsisting in any class of work). Accordingly, the aims and objectives of the two legislations are manifestly different. Also, unlike the Patents Act, (which contains provisions to redress abusive conduct when a patentee refuses to grant a license on reasonable terms), the Copyright Act only provides for a compulsory license in case of works withheld from public. ${ }^{103}$ At this juncture, it is relevant to point out that the Copyright Act would be viewed as a 'special' statute vis-à-vis the Competition Act (owing to the fact that it is a self-contained code) which would give it primacy in case of a conflict between the two. However, the two statutes do not have to be construed in such a manner, especially, since both do not have absolute non-obstante clauses. While the Competition Act does provide that the provisions of the Act shall have overriding effect notwithstanding anything contrary contained in other law, that provision is tempered by Section 62 which provides as follows: 'The provisions of this Act shall be in addition to, and not in derogation of, the provisions of any other law for the time being in force.'

Therefore, the provisions of the Copyright Act and the Competition Act have to be construed harmoniously and it cannot be said that either legislation supersedes the other. In Telefonaktiebolaget LM Ericsson v Competition Commission of India

\footnotetext{
${ }^{102}$ ibid.

${ }^{103}$ Copyright Act 1957, s 31.
} 
and Another, ${ }^{104}$ the Delhi High Court was of the opinion that the two enactments, viz. The Patents Act 1970 and the Competition Act 2002 can be construed harmoniously as the Controller of Patents can be mandated to take into account 'any finding of anticompetitive practice, that is returned after a judicial or administrative process including by the CCI under the Competition Act, while settling the terms of a compulsory license issued to remedy such practice.' 105

Accordingly, it appears that the Commission can indeed apply the EFD in a case of refusal to provide interoperability protocol to mobile wallet companies.

\section{Conclusion}

After a discussion on UPI (and its much vaunted interoperability benefit), the validity of the impugned RBI Master Direction, the parallels between the EC and $\mathrm{CCI}$, and a threadbare discussion on the EFD in the EC, a definitive conclusion can be reached. EFD can be implemented when confronted with the protective cover that is provided by IPRs. The contravention of the Competition Act under Section 4 can be established under many potential heads listed in Section 4. For instance - 'restricting technical development' under Section 4(2)(b)(ii) by preventing the addition of a new feature in mobile wallets, 'denial of market access' under Section 4(2)(c) by banks by preventing the mobile wallet companies from accessing the interoperability protocol that is available to others and 'leveraging' under Section 4(2)(e) by banks trying to secure the downstream market of mobile wallets for themselves to the exclusion of the existing players.

Disclosure: The authors wish to point out that the views expressed in this chapter are their own and do not necessarily reflect the policy or position of the Competition Commission of India.

\footnotetext{
${ }^{104}$ Telefonaktiebolaget LM Ericsson v CCI (2016) Delhi High Court, WP(C) 464/2014 and CM Nos 911/2014 \& 915/2014.

${ }^{105}$ ibid.
} 
Open Access This chapter is licensed under the terms of the Creative Commons Attribution 4.0 International License (http://creativecommons.org/licenses/by/4.0/), which permits use, sharing, adaptation, distribution and reproduction in any medium or format, as long as you give appropriate credit to the original author(s) and the source, provide a link to the Creative Commons license and indicate if changes were made.

The images or other third party material in this chapter are included in the chapter's Creative Commons license, unless indicated otherwise in a credit line to the material. If material is not included in the chapter's Creative Commons license and your intended use is not permitted by statutory regulation or exceeds the permitted use, you will need to obtain permission directly from the copyright holder.

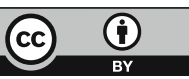

